\title{
WEBLOGGING: Implementing Communities of Practice
}

\author{
Leiser Silva \\ Elham Mousavidin \\ Lakshmi Goel \\ University of Houston \\ Houston, TX U.S.A.
}

\begin{abstract}
This paper centers on the emergent phenomenon of weblogging. Even though the total number of weblogs is increasing at an exponential rate, little formal study has been done on this phenomenon. This paper provides two main contributions. First, it describes the phenomenon of weblogging and conceptualizes it, discussing significant attributes of weblogs that set it apart from traditional communication means. Second, it establishes a framework grounded in the theory of communities of practice that provides a lens to study the potential role of weblogging in organizational communication. The research approach is qualitative and analysis is done by interpreting the content of a weblog through a hermeneutic approach. Weblogging can be seen to foster social inclusion based on its characteristics and nature. Our study shows that by its features of interaction and informality, weblogging cultivates social inclusion, particularly that of employees working in a corporation. The paper concludes by reflecting on the potential of weblogging for enabling informal means of communication in organizations.
\end{abstract}

\section{INTRODUCTION}

A weblog (or blog) is a self-publishing website that is updated on a regular basis. The word blog has been defined by the Merriam-Webster dictionary as "a web site that contains an online personal journal with reflections, comments and often hyperlinks" and has been identified as the most looked-up word in the year 2004. ${ }^{1}$ Contents of a

${ }^{1}$ BBC News, "Blog" Picked as Word of the Year," December 1, 2004; see http://news.bbc.co.uk/2/hi/technology/4059291.stm.

Please use the following format when citing this chapter:

Silva, L., Mousavidin, E., and Goel, L., 2006, in IFIP International Federation for Information Processing, Volume 208, Social Inclusion: Societal and Organizational Implications for Information Systems, eds. Trauth, E., Howcroft, D., Butler, T., Fitzgerald, B., DeGross, J., (Boston: Springer), pp. 295-316. 
weblog are written mostly in a casual manner and are archived reverse chronologically. The number of blogs continues to grow. Approximately 25.8 million blogs were being tracked by Technorati, a real-time search engine that maintains updated information on blogs, in January $2006 .{ }^{2}$ As blogs become an increasingly familiar sight on cyberspace and tools further improve, the prevalent exponential trend in growth is expected to continue (Schiano et al. 2004).

Organizations are increasingly adopting weblogs due to their dynamic and informal nature. Corporations such as Microsoft, Sun Microsystems, Google, and Yahoo, amongst many others, have recognized the potential of using weblogs, and maintain their own weblogs (Rosencrance 2004; Taulli 2006). These weblogs provide real-time information and enable all visitors to give feedback. Weblogs are a two-way channel of communication between customers and firms. They also enable informal communication among employees within an organization. In a sense, weblogs can be seen to give organizational voice to employees. Through weblogs, employees that would not usually "speak up" or participate-due to reasons that are based on personality, gender, or geographic location (Bowen and Blackmon 2003)- have a channel to express their opinion. By analyzing the phenomenon of weblogging, this paper identifies the characteristics of weblogs which make this happen. We argue that weblogs facilitate social inclusion of voices that may not have been heard in the absence of this form of communication.

The social dynamism of weblogs is manifested through different applications ranging from personal diaries to political forums. For example, in the 2004 U.S. Presidential election, weblogs were extensively used by political parties. Presidential candidate John Kerry had his own official weblog ${ }^{3}$ to communicate with supporters, obtain their feedback, and provide information about the campaign. At the same time, CNN had its own official weblog ${ }^{4}$ to provide up-to-date information about the ongoing election process. The social impact of weblogs was evident early in the night of the election in the strong belief that John Kerry was winning. This belief stemmed from the exit poll results that were published on weblogs even though the mainstream broadcasting media did not announce them.

Thus, given the relevance of weblogs, manifested in their exponential growth and their impact in mass media as well as in corporations, we decided to conduct an interpretive study (Walsham 1995) to examine their main attributes. Accordingly, the objective of this paper is to conceptualize weblogs; that is, to establish their properties and attributes as well as to propose a theoretical lens that would help researchers and practitioners make sense of this phenomenon.

The organization of the paper is as follows. We begin by defining weblogs; we do so by identifying the attributes that distinguish them from other Internet based communication technologies. We then discuss our theoretical lens, communities of practice (Brown and Duguid 1991, 1998; Lave 1991; Lave and Wenger 1991; Wenger 1998, 2000; Wenger et al. 2002; Wenger and Snyder 2000). In the subsequent section, we

${ }^{2}$ See http://www.technorati.com.

${ }^{3}$ The page, located at http://blog.johnkerry.com/blog/archives/week_2004_10_31.html, while still a valid site, is currently inactive.

${ }^{4}$ Located at http://www.cnn.com/2004/ALLPOLITICS/blog/10/13/one.blog/index.html. 
apply this lens to conduct a hermeneutic interpretation (Sanders 1982) of a corporate blog. This interpretation allows us to propose a model for understanding the life cycle of a corporate weblog. We conclude by reflecting on the potential impact of weblogging on organizational communication.

\section{WEBLOGGING}

\subsection{Attributes of Weblogs}

Early versions of what is known as a weblog today (i.e., traditional websites) are in the form of static or noninteractive web pages. Weblogs usually have a central theme and attract regular visitors who interact and form interlinked micro-communities (Herring et al. 2005; Kumar et al. 2003). This interaction is the basis for the dynamic nature of weblogs. Some popular weblogs, for example Glenn Reynolds' site, ${ }^{5}$ are visited by as many as 100,000 readers each day. ${ }^{6}$ The content of weblogs is mainly text. However, weblogs can support photos and other multimedia content as well. The posts center around the main theme of the weblog, ${ }^{7}$ with links to other weblogs or websites on the Internet. Most weblogs allow readers to leave their comments on existing posts (Blood 2002). Hence weblogging lends itself appropriately for task-related collaboration as well as informal communication. It can also be a channel for distributing information in organizations (e.g., notification of organizational decisions), two-way stakeholder communication (interaction with customers or vendors), team-building (exchange of ideas, brainstorming), informal dialogs, and problem solving. Most weblogs today feed into RSS-aware programs called aggregators. RSS (really simple syndication) is a format that syndicates information items from other websites, weblogs, wikis, or even changelogs of concurrent versions system (CVS) check-ins. An organization can use an aggregator by checking RSS feeds of news websites, new additions on supplier websites, technical updates, etc.

\subsection{Strengths}

Weblogs are created and read by individuals who share similar interests and who want to interact and communicate with like-minded people. In contrast with traditional communication systems that are usually formal and top-down driven, weblogs offer an informal and dynamic means to share information. They offer a platform for meeting and sharing ideas at one's convenience and hence enable communication between people that might not have been possible face-to-face. This engenders inclusion of indi-

\footnotetext{
${ }^{5}$ http://www.instapundit.com/

6"Blogging is Booming," R. E. Bruner (http://www.imediaconnection.com/content/ 3162.asp).

${ }^{7}$ Weblogs can have different themes. There are community weblogs (such as Metafilter), corporate weblogs (Yahoo) and weblogs that concentrate on philosophical discussions (www.plastic.com).
} 
viduals and encourages participation. With the tools available today, weblogs require minimal technical skills to setup, use, and maintain. In addition, weblogs can support multiple users in terms of accessibility for reading as well as making contributions. Weblogs, known as mBlogs, can also be accessed through mobile devices. Intranet webogs can be accessed organization-wide. A fast search feature enables archived information to be retrieved quickly. The ease of use and ubiquitous access allows inclusion of people with limited technical knowledge.

Dynamism and interaction exhibited by weblogs come from allowing users to post new topics as well as comment or reply to previous posts. Being highly interactive, weblogs are "hit" at a higher rate than static or conventional websites. Since search engines work on factors such as content relevance, number of incoming links from other sites, and rate of updating, use of weblogs increases the presence of an organization in cyberspace. Weblogs enable businesses to publish and disseminate information faster than e-newsletters or other conventional forms of electronic communication. Weblogs also have the potential to help organizations reduce costs related to storing digital information. Even though storage cost is decreasing steadily, it still remains a problem. E-mailing or sending out e-newsletters to individual employees may cause clutter in their mailboxes and decrease available storage space. Bad housekeeping habits of employees in keeping their mailboxes "clean" can further aggravate storage problems. Maintaining a central weblog to provide the same information prevents these conceivable problems by organizing the information in one location for easier reference.

\subsection{Challenges}

Despite its potential, blogging, as a new technology, is not devoid of challenges. One of those is the high abandonment rate. Due to the ease and fairly low requirements for installing them, many users set up their own blogs. However, not all blogs are read consistently and have an ardent membership. Most of them simply are not visited at all. In the terminology of bloggers these blogs are "unpopular." The popularity differentiates a successful weblog from one that is doomed to failure. This results in unnecessary clutter of inactive blogs. Furthermore, since weblogs enable informal communication, employees may easily misuse them. Weblogs may result in a waste of company resources as employees use them for entertainment and leisure.

Another important concern is that weblogs, being a source of documented information, can cause legal problems because of breaches of privacy and confidentiality. This is a risk particularly for employees who own personal weblogs that identify them with the companies for which they work. Accidental references may lead to action against the company for libel or defamation, leakage of sensitive information, data protection, and confidentiality issues (Twist 2005). Hence, most companies are concerned about the content of the personal weblogs that their employees maintain. This concern at times has led to several employees being fired or banned from publishing on their weblogs. For example, in November 2004, Delta Air Lines fired one of its flight attendants because she had pictures of herself posing in her work uniform posted on her weblog (Twist 2004). This tension between the rights of individuals to express themselves and the confidentiality required by corporations for which they work has been the 
center of attention of other academics. For instance, Suitt et al. (2003) tell the fictional story of an individual whose messages in her blog affected the reputation of the company that employed her, and eventually hit the company's revenue.

The marked interest of companies in the content of their employees' weblogs seems clearer in the field of journalism. For example, Boese (2004) wrote about two journalists, Josh Kucera from Time Magazine and Kevin Sites from CNN, whose weblogs were banned by their employers. Both journalists wrote about the Iraq war on their weblogs. According to Boese, the writings of these journalists were found to be more immediate and compelling than what appeared in Time and on CNN. Therefore, Time and CNN prohibited these journalists from publishing on the web to protect the companies' images. In another instance, Palser (2003) wrote about the story of three journalists' weblogs that were stopped prematurely because the employers of these journalists believed that those weblogs were a conflict of interest. As seen in several cases, the lack of explicit rules has created some problems for employers and their blogging employees. Legal expert Nick Locket from hi-tech DL Legal says, "Blogs can be good for companies, but what is clear is that the rules on blogs are hazy and inconsistent, and bloggers should be alert about what they are doing" (Twist 2005, p. 1).

All these features suggest the potential and limitations of weblogging for enabling communications in firms. This is relevant given the challenges faced by organizations in managing communications and information exchange (Alavi and Leidner 2001; Cole 1998; Davenport and Prusak 1997; Nonaka and Takeuchi 1995). In order to highlight the attributes of weblogging, we compare it with other means of electronic communication. A summary of this comparison is presented in Table 1.

\section{THEORETICAL BACKGROUND}

In this section we introduce our theoretical lens: communities of practice (Brown and Duguid 1991, 1998). Communities of practice posits a social theory of learning (Lave 1991; Lave and Wenger 1991; Wenger 1998, 2000; Wenger et al. 2002). From this perspective, learning is conceived as the generation and transmission of tacit knowledge through the sharing of experiences mainly through narratives and informal communications (Boland and Tenkasi 1991; Lave 1991; Lave and Wenger 1991; Wenger 1998,2000). Since organizations apply weblogs to communicate in an informal and interactive manner with their employees and customers, often with the purpose of managing knowledge (Jantsch 2004, Manjoo 2002), ${ }^{8}$ we argue that communities of practice is an appropriate lens for looking into the weblogging phenomenon. Accordingly, below we discuss in detail the different concepts of the theory of communities of practice and how they are related to our study.

${ }^{8}$ Given the scope of this paper, its purpose is not to contribute to the theory of communities of practice (although interesting) but to use it as a lens to make sense of corporate weblogs. 
Table 1. Weblogging and Conventional Electronic Media

\begin{tabular}{|c|c|c|c|c|c|c|c|c|c|c|}
\hline \multirow[b]{2}{*}{ Medium } & \multicolumn{10}{|c|}{ Attributes } \\
\hline & 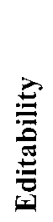 & 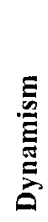 & 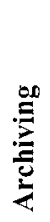 & 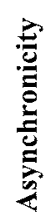 & 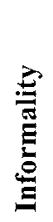 & 范 & 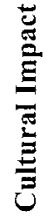 & 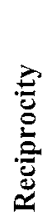 & 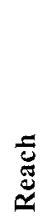 & 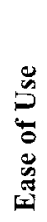 \\
\hline Newsgroups & $\mathrm{L}$ & $\mathrm{M}$ & $\mathrm{M}$ & $\mathrm{H}$ & $\mathrm{M}$ & $\mathrm{L}$ & $\mathrm{L}$ & $M$ & $\mathrm{M}$ & $\mathrm{M}$ \\
\hline Bulletin Boards & $\mathrm{M}$ & $\mathrm{M}$ & $\mathrm{M}$ & $\mathrm{H}$ & $M$ & $\bar{M}$ & $\mathrm{~L}$ & $\mathrm{M}$ & $\bar{M}$ & $\mathrm{M}$ \\
\hline E-mail, E-Newsletters & $\mathrm{N}$ & $\mathrm{N}$ & $\mathrm{L}$ & $\mathrm{H}$ & $\mathrm{M}$ & $\mathrm{L}$ & $\mathrm{L}$ & M & $\mathrm{L}$ & $\mathrm{H}$ \\
\hline Instant Messaging & $\mathrm{N}$ & $\mathrm{N}$ & $\mathrm{L}$ & $\mathrm{H}$ & $\mathrm{H}$ & $\mathrm{L}$ & $\mathrm{L}$ & $M$ & $\mathrm{~L}$ & $\mathrm{M}$ \\
\hline Groups & $\mathrm{N}$ & $\mathrm{H}$ & $\mathrm{H}$ & $\mathrm{H}$ & $M$ & $\mathrm{~L}$ & $\mathrm{M}$ & $\mathrm{H}$ & $\mathrm{M}$ & $M$ \\
\hline Open Source Systems (Wiki) & $\mathrm{H}$ & $\mathrm{H}$ & $\mathrm{H}$ & $\mathrm{H}$ & $\mathrm{M}$ & $\mathrm{L}$ & $\mathrm{L}$ & $\mathrm{H}$ & $\mathrm{H}$ & $\mathrm{M}$ \\
\hline Video Conferencing & $\mathrm{N}$ & $\mathrm{H}$ & $\mathrm{N}$ & $\mathrm{L}$ & $\mathrm{M}$ & $\mathrm{M}$ & $\mathrm{L}$ & $\mathrm{M}$ & $\mathrm{L}$ & $\mathrm{L}$ \\
\hline Websites & $\mathrm{H}$ & $\mathrm{M}$ & $\mathrm{L}$ & $\mathrm{N}$ & $\mathrm{L}$ & $\mathrm{L}$ & $\mathrm{L}$ & $\mathrm{N}$ & $\mathrm{H}$ & $\mathrm{H}$ \\
\hline Weblogging & $\mathrm{H}$ & $\mathrm{H}$ & $\mathrm{H}$ & $\mathrm{H}$ & $\mathrm{H}$ & $\mathrm{L}$ & $\mathrm{H}$ & $\mathrm{H}$ & $\mathrm{H}$ & $\mathrm{H}$ \\
\hline
\end{tabular}

Notes: $1 . \quad \mathrm{L}=$ Low $\mathrm{M}=$ Medium; $\mathrm{H}=$ High; $\mathrm{N}=$ None

2. The attributes were identified after careful examination of several weblogs, including those of Google, CNN, Microsoft, and conventional electronic media (i.e., e-mail, video conferencing, and databases) (Karahanna and Limayem 2000; Ngwenyama and Lee 1997; Yates and Orlikowski 1992).

Editability: Ability to change previously posted information

Dynamism: Rate of change/updating

Archiving: Ability to maintain records and provide search features

Asynchronicity: Ability to respond at one's convenience

Informality: Ability to express information in an informal manner

Cost: Cost of implementation, use, and maintenance

Cultural Impact: Ability to support and foster a social function

Reciprocity: Ability to support two-way communication

Reach: Number of (unspecified) recipients

Ease of Use: Effort of implementation, use, and maintenance

\subsection{Communities of Practice}

A community of practice has been defined by Brown and Duguid $(1998$, p. 96) as

A group across which know-how and sensemaking are shared the group which needs to work together for its dispositional know-how to be put into practice.... In the course of their ongoing practice, the members of such a group will develop into a de facto community. (Often, the community, like the knowledge, is implicit).

This theory assumes that such communities of practice can span across an organization, or between organizations, and are extremely flexible. Their formation is driven by a common interest to share and exchange information. They are like a "spiral 
of knowledge" in which individuals' knowledge transforms and builds upon others knowledge to form social and organizational level knowledge (Nonaka 1994). Nonaka's "knowledge creation spiral" concept centers on how knowledge through practice and communities play a symbiotic role. Communities of practice embody this symbiosis to form a unit that generates collective knowledge. Wenger $(1998,2000)$ emphasizes the informal and pervasive nature of communities of practice and highlights the aspect of learning as a practice of engaging and participating with other community members. Next, we discuss different attributes of communities of practice and how they are related to weblogging.

\subsection{Weblogging and Communities of Practice}

In conceptualizing communities of practice, Brown and Duguid (1991) identified the key attributes that define a community of practice. These are a collective cooperative venture, synergistic potential, informal support, reach and reciprocity, and interactivity, participation and learning. Using these attributes as a lens, we reflect on how blogs can support the formation of communities of practice. Table 2 contains a summary of this discussion.

A collective, cooperative venture: Communities of practice start with a group of people who have the ability and desire to share common interests. In this sense, media such as e-mail, video conferencing and instant messaging that are either one-to-one or one-to-many (usually a limited number) may not necessarily be the most appropriate media for sharing "group" interests dynamically and in an interactive way. Weblogging, since its inception, has been used for exactly the purpose of communication between like-minded individuals and is strongly a many-to-many medium, fitting the requirement of a collective, cooperative venture. Weblogs are being used by people who share common interests such as literature, nature, adventure sports, particular technologies, and research.

Synergistic potential: Communities of practice are synergistic in nature as they foster communication and sharing of knowledge and ideas in a conversational form. We may consider this way of facilitating communication as continuous. Newsgroups, bulletin boards, e-mail, and open source systems, ${ }^{9}$ on the other hand, are discrete in the sense that they do not allow a dialogical way of communication, and hence do not facilitate dynamic conversational exchange. Weblogging provides a technological platform for enabling synergistic interchange as it allows dynamic and interactive sharing of knowledge. This is achieved because the information on a weblog is available to many people at the same time and also because anyone can contribute to what is already pub-

\footnotetext{
${ }^{9}$ Weblogs employing technologies such as XML and PHP may also be considered open source systems. However, for the purpose of this paper, we choose to differentiate between such weblogs and more traditional open source systems such as wikis. We make this differentiation based on the purpose of traditional open source systems such as Linux and Wikipedia, which is to achieve a final goal and thus allows members to edit or "correct" previous posts. In weblogs, the goal is usually to express individuals' opinion and is not under the censorship of subsequent posters.
} 
Table 2. Communities of Practice Versus Weblogging

\begin{tabular}{|c|c|c|c|c|c|}
\hline Weblog & 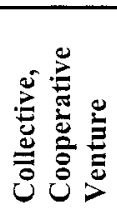 & 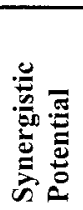 & 爵咅 & 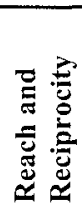 & 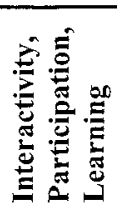 \\
\hline Editability & & & $\bar{Y}$ & & $\bar{Y}$ \\
\hline Dynamism & $\mathrm{Y}$ & $\bar{Y}$ & & $\mathrm{Y}$ & $\mathrm{Y}$ \\
\hline Archiving & & & & & $Y$ \\
\hline Asynchronocity & & & & $\mathrm{Y}$ & $\mathrm{Y}$ \\
\hline Informality & $\mathrm{Y}$ & $\mathrm{Y}$ & $\bar{Y}$ & & $\mathrm{Y}$ \\
\hline Cost & $\mathrm{Y}$ & & $\bar{Y}$ & $\bar{Y}$ & $\bar{Y}$ \\
\hline Cultural Impact & $\bar{Y}$ & $\bar{Y}$ & $\bar{Y}$ & & $\bar{Y}$ \\
\hline Reciprocity & $Y$ & $Y$ & & $\bar{Y}$ & $Y$ \\
\hline Reach & $\bar{Y}$ & & $\bar{Y}$ & $\bar{Y}$ & \\
\hline Ease of Use & $\bar{Y}$ & $\mathrm{Y}$ & $\bar{Y}$ & $\mathrm{Y}$ & $\mathrm{Y}$ \\
\hline
\end{tabular}

lished. For example, companies such as Microsoft use weblogging for exchange of ideas among developers. It conducts activities such as brainstorming for developing new products, troubleshooting, and customer relations. Weblogs can hence be used to accumulate ideas and knowledge and generate some synergistic output, whether it is in the form of an idea, a solution, or a product.

Informality: One of the key attributes of a community of practice is that its members interact casually. The level of interaction grows in an atmosphere of informality. Formality, demanded by most electronic communication media used today (such as bulletin boards and e-newsletters), thwarts this attempt at creating an informal atmosphere. Most of these groups are moderated and have a formal tone in their communications. The implicit informal nature of weblogging can greatly support communities of practice. For example, in the field of education, weblogs are being used to facilitate informal communication between students and professors (Stiler and Philleo 2003). Schools such as Harvard University ${ }^{10}$ and University of California, Berkeley ${ }^{11}$ provide weblogs to their students. Low cost, its informal tone and accessibility (blogs can be accessed through a browser) make blogs appealing to students.

Reach and Reciprocity: Members of a community of practice are accessible to other members and they engage in dialogical actions. We argue that weblogs allow for reach and reciprocity to a higher degree than other Internet communication technologies. Traditional websites, while having a global reach, do not have reciprocity. Media such as e-mail have high reciprocity but negligible reach. In contrast, weblogs, by virtue of their public and interactive attributes, not only have global reach but also facilitate

\footnotetext{
${ }^{10} \mathrm{http}: / /$ blogs.law.harvard.edu/

"http://blog.berkeley.edu/index.jsp
} 
multidirectional information exchange. Companies such as Yahoo and Microsoft use weblogs to reach their customers and engage in a dynamic exchange of information.

Interactivity, Participation, Learning: Communities of practice learn and grow as the level of interaction and participation of their members increases (Wenger 1998, 2000). In comparison with weblogs, media such as instant messaging, newsgroups, video conferencing and traditional websites have lower learning functions associated with their usage. In contrast, weblogging - by virtue of its archival and interactive features--is extensively used by journalists (Matheson 2004), lawyers, politicians, teachers (Stiler and Philleo 2003), and developers to retrieve and share collective knowledge. Thus, the weblogs' capacities to store information and provide multidirectional communication enable the reciprocity property of communities of practice.

\section{RESEARCH APPROACH}

To achieve our research objective we conducted an interpretive study (Walsham 1995 ) in which the unit of analysis is a corporate weblog. Because of its emphasis on meanings, we considered that an interpretive approach was the most suitable for conducting this research given the nature of our data (i.e., the content of a weblog). In this section we explain the rationale for the selection of the blog and how we interpreted the data.

\subsection{Selecting the Corporation}

To select the weblog we did an Internet search and looked for weblogs that were implemented by major organizations. In addition, we scanned business articles that talked about corporate weblogging (Bentley 2003; Gartenberg 2003; Jantsch 2004; Leonard 2003; Macdonald 2004; Malik 2003; Manjoo 2002; Miller 2003; Verton 2003; Weidlich 2003). Some weblogs that were mentioned frequently in the media and were found as top search results on the Internet are

- Google, http://googleblog.blogspot.com/

- Yahoo, http://www.ysearchblog.com/

- Sun Microsystems, http://blogs.sun.com/roller/main.do

- Jupiter Research, http://weblogs.jupiterresearch.com/toplevel/

- Macromedia, http://weblogs.macromedia.com/mxna/reports/categoryFeedReport/

- GM, http://gmblogs.com/

- Microsoft, http://blogs.msdn.com/

The content of these weblogs was scanned. Statistics such as their duration, central theme, and readership were observed. Microsoft was chosen because it was one of the early adopters of weblogs as a communication technology and has implemented them for a variety of applications including technical discussions, personal opinions, brainstorming, and customer support (Evers 2004; Miller 2003). 


\subsection{Selecting the Blog}

In addition to online help, documentation, and technical support, Microsoft hosts what they call "Microsoft Technical Communities." These Communities facilitate communication exchanges through different tools such as webcasts, online chats, user groups, and weblogs. Microsoft maintains a community ${ }^{12}$ of weblogs, which covers 129 categories such as Microsoft products, technologies, research, and applications. There are around 700 different weblogs owned by Microsoft employees. With the purpose of selecting our unit of analysis (i.e., the corporate blog), we scanned and examined the content of those blogs. A weblog called "Office Development, Security, Randomness"13 was chosen because, using our criteria, it was representative of a corporate weblog. Like other weblogs of Microsoft communities, this weblog is authored by a developer. Topics posted by the author center around issues concerning technical aspects of his work at Microsoft, as well as personal anecdotes. Primarily, posts on the weblog include things that the author finds interesting in his line of work, and things that he thinks his readers would find useful. Hence, the readership primarily consists of people who are knowledgeable about IT product development and security. The title of the weblog, "Office Development, Security, Randomness...(But mostly randomness)," implies that the author sees the weblog as an informal means of communicating with like-minded individuals. The weblog requires a login to make posts, hence there is a control on who can post. Personal weblogs in organizations are usually required to have a disclaimer on the responsibility of posts. This weblog explicitly states that neither the primary author nor Microsoft is responsible for anything on the weblog. The posts are archived reverse chronologically and can be searched according to the post categories. The statistics of the weblog are

- Name of the weblog: Office Development, Security, Randomness...

- Number of Posts: 181

- Number of Comments: 2053

- Start date: July 2003

\subsection{Interpretation}

We began by reading all posts ${ }^{14}$ and interpreting them against the backdrop of our theoretical lens. Next, we synthesized our initial interpretations in themes (Sanders 1982). This was done through a hermeneutic circle that took us back and forth from the text to theory (Klein and Myers 1999; Taylor 1971). In so doing, we classified the text into categories that corresponded to the components of the concepts of our theoretical framework. Although we found that most themes were related to those concepts, we

\footnotetext{
${ }^{12} \mathrm{http}: / / \mathrm{www} \cdot \mathrm{microsoft.com} /$ communities/blogs/PortalHome.mspx

${ }^{13} \mathrm{http}: / /$ blogs.msdn.com/ptorr

${ }^{14}$ Our data were the threads posted in the weblog. We downloaded the content from July 2003 through September 2005 and converted it into text files.
} 
also found recurring emergent themes such as commitment to post on behalf of the author, and the lack of explicit rules of language that lead the author to impose norms. Given the large volume of data, it is not possible to present all the quotes collected. Some representative quotes are mentioned in the next section to elucidate each theme. A summary of the themes and their relation to the data and theory are summarized in the Appendix.

\section{RESULTS}

We structured the themes according to what we interpreted to be the life cycle of a blog. In order to provide structure, we studied the temporal occurrence of the themes. In doing so, we found a certain sequence and identified three stages clearly demarcated in the weblog. This sequence allows us to present the themes in a coherent and systematized manner.

The first stage-- the birth of a blog-represents the beginning of a new weblog. Here the author tries to establish the tone and make clear the subject matter of the blog. Certain implicit and explicit rules are set by the author at this stage. The characteristics attained by the blog at this stage are retained through the life of the blog. The second stage occurs when the weblog matures and facilitates learning and knowledge as the result of the members exchanging communications and engaging actively in discussions. At this stage, the author and the readers relate to each other on an individual level. The third stage of the blog - its death-occurs when the author loses his commitment to post regularly. We argue that this could occur due to various reasons including decline in readership of the blog or increase in work load of the author, causing him to lose motivation to expend time on the weblog. In turn, loss of motivation of the author leads to further decline in readership. This circle, we believe, leads to the death of the blog over time. Figure 1 depicts this cycle. ${ }^{15}$

In the rest of this section, we explain in detail the different themes associated with each stage of the lifecycle and relate them to what we considered were the most representative quotations in our data. Figure 1 summarizes this discussion.

\subsection{The Birth of a Blog: Setting of Rules, Subject Matter, and Tone (Informality)}

A salient attribute of a blog is its informal tone. Thus, unlike technical forums in which there are clear rules and moderators, bloggers, as suggested above, struggle in finding rules that define boundaries of what is allowed and what is not. It is clear that one of the concerns of the owner of the blog is what he is allowed to share with his readers as seen in the following quote:

\footnotetext{
${ }^{15}$ The diagram merely provides a simplified picture, and we are aware that several factors could be brought into consideration in these dynamics. However, our objective is to illustrate our findings and represent our interpretation of the phenomenon.
} 


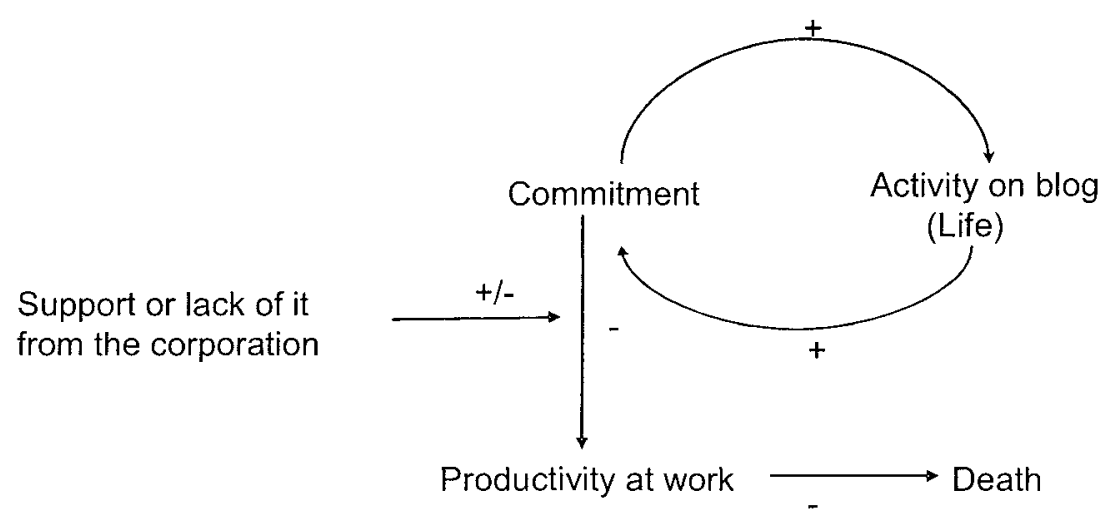

Figure 1. Life Cycle of a Corporate Blog

There's lots of stuff I'd like to write about, but it's not very clear if they're "permitted" topics.

Indeed, this can be an inhibitor for posting on the blog. Another rule that we grasp from our interpretation is the need for the messages to be "legitimate."

Thanks to the people who leave legitimate comments on the blog.

By legitimate, we interpret that the owner of the blog means that the messages have to be faithful to the main theme, which is of a technical nature. However, as we will see below, this does not mean that the participants do not discuss other topics in which they are interested. We found that the language of the blog is casual. This is not explicit anywhere but it is implicitly a common theme in the whole blog. This can be appreciated in the following quote:

Today I needed to write a fairly simple piece of code to manipulate some Excel documents, and I chose to do it in VBA. That might sound like heresy for someone who used to work on Visual Studio Tools for Office, but since I switched teams I feel no obligation to use that stuff any more ;-)

The tone is not only friendly but also reveals interiorities of the work at Microsoft. This warmth and casual language invites people to contribute and also portrays a friendly face of the work at Microsoft. Technical knowledge is also presented in an informal and humorous manner, as illustrated in the following quote:

But here I present three easy ways you can disable WSH [Windows Script Host] if you so wish (ha ha, pun intended:-)).

This relates to the attribute according to which communities of practice share information in a casual manner. We may argue here that a blog that maintains a formal and 
cold tone would not get too many visits. The same argument can be made about inflammatory remarks, which are not only illegitimate but also unfriendly. The owner of the blog tries to prevent flaming as it would undermine the popularity of the blog and probably deter legitimate participants:

Yes, please don't have a flame war on my blog 9 I will delete any flames...

\subsection{The Life of a Blog: Personal Touch-Creation of Knowledge Occurs through Dialogue (Interactivity, Participation, Learning; Collective Cooperative Venture)}

We observed how participants of the blog engaged in searching for solutions. Participants' interaction and replies to posts, which were on first-name basis, facilitated arriving at technical solutions.

The other day, Karl Levinson added a comment to my previous entry about the Outlook OM. He raises some interesting points, so I thought I'd reply here... The comments from my last post are still coming in thick and fast... Thanks for being part of the solution! :-)

In the above quote we observe that the messages posted correspond to the sequence in which the topic is being discussed. It shows that the owner of the blog pays attention and reads the messages. We argue that it is essential for the blogger to demonstrate commitment to his readers. This commitment is accompanied not only by the quality of the content, but also by honesty.

First things first: I was wrong about uninstalling plug-ins. Thanks to several helpful posters, you can actually do this via ...

We can only assume that the readers and participants of the blog sympathize with the openness and honesty of a Microsoft programmer acknowledging that he has been wrong. In addition, the dialogical and personal touch of the blog is observed since the owner of the blog takes personal care of the participants in offering technical solutions.

Based on some of Nicole's feedback, I decided to write a basic app that checked your. NET security settings for you...

We found that the personal touch of the owner of the blog was key for the members to participate in posting messages. This is reflected, for example, in the fact that the blog, in addition to the main technical theme, also allows people to comment on other areas of interest of the owner of the blog, such as coffee.

As I blogged earlier (I think!) I have a rather nice espresso machine at home. You can pick one up for yourself at Whole Latte Love (that pun makes my dear 
friend wince :-)) but it's a bit big (and expensive) to have one at work as well, so I took advantage of this really cool offer from illy to get a Francis Francis! $X 5$ machine for only $\$ 175$. (The catch: you have to buy a year's worth of coffee to go with it).

Although, clearly this is not the thread that gets the majority of comments, it is, in our view a fundamental component in which the owner of the blog portrays himself as an individual, not as an official, impersonal, or even cold Microsoft employee. We argue that an impersonal blog would not become popular.

\subsection{Death of a Blog: End of its Life Cycle}

We argue that the dialogical nature of the communication and the personal touch and commitment of the blogger are essential for boosting participation in the blog. These are what make the blog popular. We found that there is a virtuous circle between popularity and commitment that gives life to the blog (see Figure 1). It is the popularity of the blog that makes the owner continue posting. This is illustrated in the following quote:

\section{It would be nice to know how many people (if any) actually read this. Kind of gives one an incentive to write.}

Clearly, maintaining this blog is an advantage for Microsoft for improving its image and collecting information from its customers regarding their technical problems. The downside is probably that keeping up with the popularity and expectations of this weblog requires a serious commitment in terms of time and effort on behalf of the employee. This would eventually impact the weblogger's productivity. Moreover, if the weblogger's superiors do not consider his blogging activity as a part of his job duties, the blogger might get into trouble. This in turn might result in less frequent posts. Therefore, we conjecture that one of the reasons a blog may "die" is when the owner cannot keep the level of commitment that makes a weblog popular. In other words, blogs can become victims of their own success. Though there may be other reasons that a blog might die, we argue that the ability and the motivation of the author are key for its life. The ability of the author relates to factors such as support from his organization, time available to him, and his subject knowledge on the topic of the weblog. Since these factors cannot be observed in the data (as they relate to the death of the blog), we formulate this assertion as a conjecture that would require empiric confirmation.

From the data, we observe that the motivation to post comes from the readership and feedback from the readers. When the owner does not post, readers (including other bloggers) stop visiting and posting and that is the beginning of the end. The owner of this blog, conscious of this issue, posted the following message:

Just a quick message to anyone who happens to be reading this that I'm still around. 


\section{IMPLICATIONS}

Several implications stem from the analysis of our data. Some are theoretical, such as our proposed life cycle of a corporate blog and the themes that emerged from our interpretation. These could be subject to confirmatory studies. Moreover, it would be interesting to establish whether other types of blogs exhibit similar properties. We also found that blogs, by means of their informality and interaction, can support communities of practice. In this sense we consider that such a lens is an appropriate theoretical framework for examining blogs. As seen in our analysis, blogging is more than a mere technical phenomenon. It encompasses social and psychological aspects such as group norms and the personality of the blogger. Implicitly setting group norms and rules is vital for the community to be coherent. In terms of the personality of the blogger, we found that an openness to share some aspects of his/her work and personal life are important, as are writing and communication skills. Accordingly, blogs can facilitate social inclusion, as individuals with those particular personality traits can express their thoughts and discuss ideas with other people. Blogs are different from other similar media, such as forums and wikis, in the fact that the blogs are mostly owned by individuals. Since they eliminate social structures, such as membership, and technical barriers due to their technological attributes, such as ease of use and interactiveness (Herring et al 2005), weblogs are suitable for social inclusion on the Internet.

In terms of implications for practice, we found that a corporation interested in deploying blogs as a media of communication with their customers may gain valuable benefits. Concretely, we identify two. One is the opening of their organization and the displaying of a "human side" to their organization. This was clear in our data, particularly when the Microsoft blogger openly shared with his readers interiorities of his work and personal tastes. The other benefit we see is that organizations may gain knowledge of the perception and performance of their products. Accordingly, Microsoft would learn about the problems of their products as well as the meaning that these problems have for their customers. Furthermore, they can offer much more personalized support through blogs. Another practical implication is that managers considering supporting blogs to communicate with customers should bear in mind that employees are going to commit valuable and considerable resources to the maintenance of the blog. Therefore, encouraging the employees to blog and allowing them to spend time as part of their job function is important. As implied by the life cycle proposed in this research, the support from the corporation plays a vital role in popularity or death of a blog. These practical implications are additions to the already known considerations about privacy and confidentiality that are problematic in most new technologies.

\section{LIMITATIONS AND FUTURE RESEARCH}

In conceptualizing the phenomenon of blogging, we have employed a framework grounded in the theory of communities of practice. We analyzed a blog using our theoretical lens and have proposed a model that represents the life cycle of a corporate blog. Given the scope of this research, we have only succeeded in providing a holistic view of the phenomenon. However, each theme that we found can be researched in 
more depth. For example, elements of the proposed model can be investigated in further studies. Likewise, the social and psychological aspects of the phenomenon can be fullfledged topics for future research. Literature from the fields of social psychology, psychology, and organizational culture can be drawn upon and used as different lenses to study the same phenomenon. Another interesting line of enquiry could focus on identifying the different reasons for why organizational members decide to blog (i.e., corporate objectives, self promotion) and, once identified, studying how those reasons determine the way blogs evolve further. Thus, scholars can refer to this paper as a broad view on corporate blogging to identify potential topics with a narrower scope.

\section{CONCLUSION}

Internet-based practices such as blogging continue to evolve and open new possibilities for individuals and organizations. We found that the dynamism and informal attributes of blogs make them an attractive means of communication. This paper constitutes an effort to make sense of an emergent phenomenon such as blogging, whose attributes and fast growth raise a degree of perplexity to which information systems researchers cannot remain indifferent. This paper does not wish to prove that weblogs are conclusively the most effective way to enable informal communication. Sampling and statistical techniques would be needed in order to investigate that research question. Instead, we attempt to find the emergent themes in weblogs. The goal of this paper was not to develop a generalizable theory but, as Walsham (1995) and Lee and Baskerville (2003) posit, to find second order concepts as generalizations of our findings. In this paper we have articulated a set of attributes that, we argue, give blogs their unique dynamism. Moreover, we have proposed a model that depicts the possible life cycle for corporate blogs. All in all, as bloggers continue to innovate their practices and organizations adopt these practices, researchers of information systems have an exciting challenge ahead.

\section{References}

Alavi, M., and Leidner, D. E. "Review: Knowledge Management and Knowledge Management Systems: Conceptual Foundations and Research Issues," MIS Quarterly (25:1) 2001, pp. 107-136.

Bentley, R. "Blogging Touted as a New Business Tool," Computer Weekly.com (8), September 22, 2003 (available online at http:/www.computerweekly.com/Articles/2003/09/22/197397/ Bloggingtoutedasanewbusinesstool.htm).

Blood, R. "We've Got Blog: How Weblogs are Changing Our Culture," Cambridge, MA, Perseus Publishing, 2002.

Boese, C. "The Spirit of Paulo Freire in Blogland: Struggling for a Knowledge Log Revolution," Into the Blogosphere, 2004 (http://blog.lib.umn.edu/blogosphere/ the spirit_of paulo_freire.html).

Boland, R. J., and Tenkasi, R. V. "Perspective Making and Perspective-Taking in Communities of Knowing," Organization Science (6:4), 1995, pp. 350-372.

Bowen, F., and Blackmon, K. "Spirals of Silence: The Dynamic Effects of Diversity on Organizational Voice," Journal of Management Studies (40:6), 2003, pp. 1393-1417. 
Brown, J. S., and Duguid, P. "Organizational Knowledge," California Management Review (40:3), 1998, pp. 90-111.

Brown, J. S., and Duguid, P. "Organizational Learning and Communities-of-Practice: Toward a Unified View of Working, Learning, and Innovation," Organization Science (2:1), 1991, pp. 40-57.

Cole, R. E. "Introduction," California Management Review (45:3), 1998, pp. 15-21.

Davenport, T. H., and Prusak, L. Working Knowledge: How Organizations Manage What They Know, Boston, MA: Harvard Business School Press, 1997.

Evers, J. "Microsoft's Channel 9 Gets Social with Developers," ComputerWorld, April 6, 2004 (available online at http://www.computerworld.com/developmenttopics/development/story/ 0,10801,91979,00.html).

Gartenberg, M. "Blogging for Fun and Profit," ComputerWorld, March 3, 2003 (available online at http://www.computerworld.com/developmenttopics/development/webdev/story/ $0,10801,78895,00 \cdot h$ tml).

Herring, S. C., Scheidt, L. A., Wright, E., and Bonus, S. "Weblogs as a Bridging Genre" Information Technology and People (18:2), 2005, pp. 142-171.

Jantsch, J. "Blogging for Business-Great Reasons for Every Business to Start a Weblog," Webpronews.com, March 24, 2004 (available online at http://www.webpronews.com/ ebusiness/smallbusiness/wpn-2-20040324BloggingForBusinessGreatReasonsFor EveryBusinessToStartAWeblog.html).

Karahanna, E., and Limayem, M. "E-Mail and V-Mail Usage: Generalizing Across Technologies," Journal of Organizational Computing and Electronic Commerce (10:1), 2000, pp. 49-66.

Kumar, R., Novak, P., Raghavan, S., and Tomkins, A. "On the Bursty Evolution of Blogspace," in Proceedings of the Twelfth International World Wide Web Conference, Budapest, Hungary, 2003, pp. 568-576.

Klein, H. K., and Myers, M. D. "A Set of Principles for Conducting and Evaluating Interpretive Field Studies in Information Systems," MIS Quarterly (23:1), 1999, pp. 67-94.

Lave, J. "Situating Learning in Communities of Practice," in L. B. Resnick, J. M. Levine, and S. D. Teasley (eds.), Perspectives on Socially Shared Cognition, Washington, DC: American Psychological Association, 1991.

Lave, J., and Wenger, E. Situated Learning: Legitimate Peripheral Participation, Cambridge, UK: Cambridge University Press, 1991.

Lee, A. S., and Baskerville, R. L. "Generalizing Generalizability in Information Systems Research," Information Systems Research (14:3), 2003, pp. 221-243.

Leonard, B. "Blogs Begin to Make Mark on Corporate Communications," HR Magazine (48:9), 2003 , p. 30

Lucas, J. W., Younts, C. W., Lovaglia, M. J., and Markovsky, B. "Line of Power in Exchange Networks," Social Forces (80:1), 2001, pp. 185-214.

Macdonald, N. "The Future of Weblogging," The Register, April 18, 2004 (available online at http://www.theregister.co.uk/2004/04/18/blogging future/).

Malik, O. "Blogging for Dollars," Business 2.0 (4:10), 2003, p. 40.

Manjoo, F. "Flash: Blogging Goes Corporte," Wired Magazine, May 9, 2002 (available online at http://www.wired.com/news/culture/0,1284,52380,00.html).

Matheson, D. "Weblogs and the Epistemology of the News: Some Trends in Online Journalism," New Media \& Society (6:4), 2004, pp. 443-468.

Miller, R. "Blogging for Business," EContent (26:10), 2003, pp. 30-34.

Ngwenyama, O. K., and Lee, A. S. "Communication Richness in Electronic Mail: Critical Social theory and Contextuality of Meaning," MIS Quarterly (21:2), 1997, pp. 145-167.

Nonaka, I. "A Dynamic Theory of Organizational Knowledge Creation," Organization Science (5:1), 1994, pp. 14-37. 
Nonaka, I., and Takeuchi, H. The Knowledge-Creating Company: How Japanese Companies Create the Dynamics of Innovation, New York: Oxford University Press, 1995.

Palser, B. "Free to Blog?," American Journalism Review (25:5), 2003, pp. 62-63.

Rosencrance, L. "Blogs Bubble Into Business," ComputerWorld, January 26, 2004 (available online at http://www.computerworld.com/softwaretopics/software/story/ $0,10801,89283,00 . \mathrm{html}$ ).

Sanders, P. "Phenomenology: A New Way of Viewing Organizational Research," Academy of Management Review (7:3), 1982, pp. 353-360.

Schiano, D. J., Nardi, B. A., Gumbrecht, M., and Swartz, L. "Blogging by the Rest of Us," in Proceedings of the Conference on Human Factors in Computing Systems New York: ACM Press, 2004, pp. 1143-1146.

Short, J., Williams, E., and Christie, B. The Social Psychology of Telecommunications, London: John Wiley \& Sons, 1976.

Stiler, G. M., and Philleo, T. "Blogging and Blogspots: An Alternative Format for Encouraging Reflective Practice Among Preservice Teachers," Education (123:4), 2003, pp 789-797.

Suitt, H., Weinberger, D., Samuelson, P., Ozzie, R., and Motameni, E. "A Blogger in Their Midst," Harvard Business Review (81:9), 2003, pp. 30-40.

Taulli, T. "Tapping into the Blogosphere," Forbes, January 25, 2006 (available online at http:/www.forbes.com/2006/01/24/google-apple-microsoft-cx_tt_0125straightup.html? partner=tentech_newsletter).

Taylor, C. "Interpretation and the Sciences of Man," Review of Metaphysics (25:71), 1971, pp. 3-51.

Twist, J. "US Blogger Fired by Her Airline," BBCNews, November 3, 2004 (available online at http://news.bbc.co.uk/1/hi/technology/3974081.stm).

Twist, J. "Looming Pitfalls of Work Blogs," BBCNews, January 3, 2005 (available online at http://news.bbc.co.uk/2/hi/technology/4115073.stm).

Verton, D. "Blogs Play a Role in Homeland Security," ComputerWorld, May 12, 2003 (available online at http://www.computerworld.com/developmenttopics/websitemgmt/ story $/ 0,10801,81115,00 . \mathrm{html})$.

Walsham, G. "Interpretive Case Studies in IS Research: Nature and Method," European Journal of Information Systems (4), 1995, pp. 74-81.

Weidlich, T. "Executive Life: The Corporate Blog Is Catching On," The New York Times, June 22, 2003 (available online at http://www.nytimes.com/).

Wenger, E. Communities of Practice: Learning, Meaning, and Identity, Cambridge, UK: Cambridge University Press, 1998.

Wenger, E. "Communities of Practice and Social Learning Systems," Organization (7:2), 2000, pp. 225-247.

Wenger, E., McDermott, R., and Snyder, W. Cultivating Communities of Practice: A Guide to Managing Knowledge, Boston: Harvard Business School Press, 2002.

Wenger, E., and Snyder, W. "Communities of Practice: The Organizational Frontier," Harvard Business Review (78:1), 2000, pp. 139-146.

Yates, J., and Orlikowski, W. J. "Genres of Organizational Communication: An Approach to Studying Communication and Media," Academy of Management Review (17:2), 1992, pp 299-326.

\section{About the Authors}

Leiser Silva is an Assistant Professor in the Decision and Information Sciences Department at the C. T. Bauer College of Business, University of Houston. He holds a Ph.D. in information systems from the London School of Economics and Political Science. His current research 
examines issues of power and politics in the adoption and implementation of information systems. In addition, he is looking at managerial aspects of information systems, specifically contextual and institutional factors as well as knowledge management systems. His work has been published or is forthcoming in journals such as MIS Quarterly, The Information Systems Journal, Journal of the Association for Information Systems, Communications of the Association for Information Systems, European Journal of Information Systems, Information Society, Journal of Information Technology for Development, and Information Technology and People. He has served as an Associate Editor for MIS Quarterly. Leiser can be reached at lsilva@uh.edu.

Elham Mousavidin is a Doctoral student in the Decision and Information Sciences Department at the C. T. Bauer College of Business, University of Houston. She received her MBA from C. T. Bauer College of Business in December 2002. Her current research interest lies in the area of Web-based communications and Web-enabled communities. She has been involved in research on Weblogs and their potential applications in organizations and is working on more papers on this topic with her coauthors. Elham can be reached at: emousavi@mail.uh.edu.

Lakshmi Goel is a Doctoral student in the Decision and Information Sciences Department at the C. T. Bauer College of Business, University of Houston. She holds a Master's in Computer Science from the University of Houston, and a Master's in Computer Applications from the University of Pune, India. Her current research looks at organizational learning and knowledge management through information systems. She is interested in strategic, socio-psychological, sociological, and managerial facets of information systems. Lakshmi can be reached at lgoel@uh.edu. 


\section{Appendix: Content Analysis}

\begin{tabular}{|c|c|c|}
\hline Quote & Interpretation & $\begin{array}{c}\text { How the } \\
\text { Interpretation } \\
\text { Relates to Cop }\end{array}$ \\
\hline $\begin{array}{l}\text { 1. "So here it goes (Jeff, I promise this will be a } \\
\text { short entry! Honest! Ha ha ha)" } \\
\text { 2. "But here I present three easy ways you can } \\
\text { disable WSH if you so wish (ha ha, pun intended :- } \\
\text { ) ):" } \\
\text { 3. "Today I needed to write a fairly simple piece } \\
\text { of code to manipulate some Excel documents, and } \\
\text { I chose to do it in VBA. That might sound like } \\
\text { heresy for someone who used to work on Visual } \\
\text { Studio Tools for Office, but since I switched teams } \\
\text { I feel no obligation to use that stuff any more ;-)" } \\
\text { 4. "Btw, didn't your mother teach you to always } \\
\text { save to disk instead of running files from the online } \\
\text { location! tut tut! (posted by a reader)" } \\
\text { 5. "People need to be trained about security issues } \\
\text { before they can effectively design, write, test, or } \\
\text { document a software product. I am sure that some } \\
\text { readers might chuckle to themselves here and make } \\
\text { a snide remark about how 'Everybody should } \\
\text { know about buffer over-runs (BOs) by now!' but } \\
\text { there are two things I want to say about that" } \\
\text { 6. "Here's a quick story about one such rule that } \\
\text { we fixed before the CLR shipped. I'm warning } \\
\text { you -- it's obscure and boring and you'll never get } \\
\text { the } 5 \text { minutes of your life back if you keep reading, } \\
\text { but someone wanted me to post about such things } \\
\text { so here goes" }\end{array}$ & $\begin{array}{l}\text { Communication is not } \\
\text { formal even though } \\
\text { the content is. }\end{array}$ & $\begin{array}{l}\text { Informal } \\
\text { support }\end{array}$ \\
\hline $\begin{array}{l}\text { 1. "Thanks for being part of the solution! :-)" } \\
\text { 2. "This post wouldn't have been possible without } \\
\text { all of the great work people at Microsoft are doing } \\
\text { around thread modeling" } \\
\text { 3. "Thanks to several helpful posters, you can } \\
\text { actually do this via Tools -> Options -> Downloads } \\
->\text { Plugins and clicking on the little blue arrows" } \\
\text { 4. "(Thanks to Mike and Robert and the other folk } \\
\text { who gave this a once-over before posting; any } \\
\text { errors are still mine though;-))" }\end{array}$ & $\begin{array}{l}\text { Readers help at } \\
\text { arriving at a solution. } \\
\text { The knowledge } \\
\text { presented in the post } \\
\text { is a cumulative result } \\
\text { from various sources. }\end{array}$ & $\begin{array}{l}\text { Synergistic } \\
\text { potential }\end{array}$ \\
\hline
\end{tabular}




\begin{tabular}{|c|c|c|}
\hline Quote & Interpretation & $\begin{array}{c}\text { How the } \\
\text { Interpretation } \\
\text { Relates to Cop } \\
\end{array}$ \\
\hline $\begin{array}{l}\text { 5. "As a lover of open source and a lover of } \\
\text { Firefox, I'd like to say thanks for your helpful } \\
\text { suggestions. I hope Firefox will take them on } \\
\text { board" }\end{array}$ & & \\
\hline $\begin{array}{l}\text { 1. "It would be nice to know how many people (if } \\
\text { any) actually read this. Kind of gives one an } \\
\text { incentive to write." } \\
\text { 2. "I thought everyone had stopped reading but } \\
\text { for better or worse I checked and there were a few } \\
\text { hundred fresh ... comments on my Firefox post" } \\
\text { 3. "Only have discovered your blog recently, but } \\
\text { I'm turning into an avid reader!" }\end{array}$ & $\begin{array}{l}\text { Author aims at a wide } \\
\text { (global) audience for } \\
\text { what he has to say. } \\
\text { Readers reciprocate. }\end{array}$ & $\begin{array}{l}\text { Reach and } \\
\text { Reciprocity }\end{array}$ \\
\hline $\begin{array}{l}\text { 1. "The other day, Karl Levinson added a } \\
\text { comment to my previous entry about the Outlook } \\
\text { OM. He raises some interesting points, so I } \\
\text { thought I'd reply here" } \\
\text { 2. "First things first: I was wrong about } \\
\text { uninstalling plug-ins. Thanks to several helpful } \\
\text { posters, you can actually do this via ..." } \\
\text { 3. "Based on some of Nicole's feedback, I decided } \\
\text { to write a basic app that checked your .NET } \\
\text { security settings for you..." } \\
\text { 4. "As I blogged earlier (I think!) I have a rather } \\
\text { nice espresso machine at home. You can pick one } \\
\text { up for yourself at Whole Latte Love (that pun } \\
\text { makes my dear friend wince ) but it's a bit big } \\
\text { (and expensive) to have one at work as well, so I } \\
\text { took advantage of this really cool offer from illy to } \\
\text { get a Francis Francis! X5 machine for only \$175. } \\
\text { (The catch: you have to buy a year's worth of } \\
\text { coffee to go with it). } \\
\text { 5. "The other day Eric Wilson asked how to } \\
\text { ensure his code never ran with FullTrust. I replied } \\
\text { that the "best" way was to refuse permissions you } \\
\text { didn't want, and then Nicole Calinoiu replied that } \\
\text { maybe requesting optional permissions was } \\
\text { better." } \\
\text { 6. "Just wanted to let you know that your } \\
\text { presentation on VSTO and VSTO2 were } \\
\text { awesome... the level of content, detail, and }\end{array}$ & $\begin{array}{l}\text { Interaction by the } \\
\text { author with readers at } \\
\text { a first name basis. } \\
\text { The author receives } \\
\text { feedback about posts } \\
\text { and rectifies errors he } \\
\text { had made. } \\
\text { Author adds a } \\
\text { personal touch by } \\
\text { giving anecdotes from } \\
\text { his life. }\end{array}$ & $\begin{array}{l}\text { Personal touch, } \\
\text { Interactivity, } \\
\text { Participation, } \\
\text { Learning; } \\
\text { Collective } \\
\text { cooperative } \\
\text { venture }\end{array}$ \\
\hline
\end{tabular}




\begin{tabular}{|c|c|c|}
\hline Quote & Interpretation & $\begin{array}{c}\text { How the } \\
\text { Interpretation } \\
\text { Relates to Cop }\end{array}$ \\
\hline $\begin{array}{l}\text { reasoning was very much appreciated. Looking } \\
\text { forward to your security talk on Office!" } \\
\text { 7. "But, I thought to myself, one way to share } \\
\text { some of my experience with all you great folks } \\
\text { would be to have a series of 'Dear Diary' entries } \\
\text { where (in the grandest tradition of trashy } \\
\text { magazines) I will publish letters from "readers" } \\
\text { who have sent me their security questions, and } \\
\text { provide my answers or advice. Some of these } \\
\text { questions will come from real engagements I have } \\
\text { had at Microsoft, some will come from questions } \\
\text { I've had from external customers in the past, and } \\
\text { (maybe) some will come from questions that you } \\
\text { send in. Then I won't have to fake it any more! :-) } \\
\text { Anyway, we'll see how it goes... I'd love to hear } \\
\text { your feedback." }\end{array}$ & & \\
\hline $\begin{array}{l}\text { 1. "Iust a quick message to anyone who happens to } \\
\text { be reading this that I'm still around" } \\
\text { 2. "A couple of people have asked me about this... } \\
\text { I just need to clean up a few things in my "copious } \\
\text { spare time' and then I'll post it to GotDotNet -- I } \\
\text { promise!" } \\
\text { 3. "Sorry for the delay :-(" } \\
\text { 4. "I'll be off-line for a few days, so no comments } \\
\text { will get moderated until I return." }\end{array}$ & $\begin{array}{l}\text { Author feels obligated } \\
\text { to post regularly } \\
\text { Author feels obligated } \\
\text { to reply to readers } \\
\text { requests } \\
\text { Author feels obligated } \\
\text { to let his readers } \\
\text { know about his } \\
\text { absence }\end{array}$ & Commitment \\
\hline $\begin{array}{l}\text { 1. "There's lots of stuff I'd like to write about, but } \\
\text { it's not very clear if they're "permitted" topics." } \\
\text { 2. "Yes, please don't have a flame war on my blog } \\
\text { I will delete any flames..." } \\
\text { 3. "Thanks to the people who leave legitimate } \\
\text { comments on the blog" } \\
\text { 4. "Thanks to everyone who didn't just swear at } \\
\text { me (and if I didn't approve your comment, it was } \\
\text { because it had too much profanity in it)" }\end{array}$ & $\begin{array}{l}\text { Implicit rules and } \\
\text { norms set by the } \\
\text { author. }\end{array}$ & $\begin{array}{l}\text { Lack of explicit } \\
\text { rules }\end{array}$ \\
\hline
\end{tabular}

